\title{
Web Sayfası Canlı Desteğin, Web Sayfası Güven ve Web Sayfası Kullanım Kalitesine Etkisi: Online Alışveriş Siteleri Üzerine Bir Araştırma
}

DOI: $10.26466 /$ opus.687398

\author{
Emine Aydınhan* - Serhat Erat ** \\ ${ }^{*}$ Gebze Teknik Üniversitesi \\ E-Posta: emineaydinhann@gmail.com \\ ORCID: $0000-0002-0479-2506$ \\ ** Doç. Dr., Gebze Teknik Üniversitesi \\ E-Posta: erat@gtu.edu.tr \\ ORCID: 0000-0003-0227-8914
}

Öz

Online alışveriş sitelerinin artması ve internete kolay erişim sağlanması, online ortamda rekabetin de artmasına sebep olmaktadır. Her geçen gün müşteriler için seçenekler artarken, e-perakendeciler için müşteri kazanmak zorlaşmaktadır. Bunun en temel sebeplerinden biri güven ve kalitedir. Satıcı güvenilir olduğunu ve kalitesini kanıtlayarak müşteri kazanmak, tüketici ise istek ve ihtiyaçlarının karşılanacağından emin olmak istemektedir. Tüketiciler ve satıcılar arasında kolay bir iletişim olması kendilerini ifade edebilmeleri açısından önemlidir. Canlı destek sistemi, çevrimiçi müşterilere gerçek zamanl ve isteğe bağhl destek sağlamak için yenilikçi bir araçtır. Bu çalışmanın amacı online alışveriş sitelerinde canlı destek sisteminin web sayfası kullanım kalitesi ve web sayfası güveni üzerindeki etkisinin incelenmesidir. Canlı desteğin web sayfası kullanım kalitesi ve web sayfası güveni üzerindeki etkisi ve aralarındaki ilişki temel olarak 8 hipotez sinaması ile incelenmektedir. Araştırma e-ticaret sitelerini kullanan 346 katılımcı üzerinde gerçekleştirilmiştir. Veriler literatürde çok sık kullanılan veri toplama yöntemlerinden biri olan anket yöntemi ile toplanmış, SPSS paket programı ile analiz edilmiştir. Araştırma sonuçları incelendiğinde canlı destek, web sayfası güven ve web sayfası kullanım kalitesi arasında poziif yönde anlamlı ilişkiler bulunmuş ve ortaya konulan hipotezler doğrulanmıştır.

Anahtar Kelimeler: Canlı Destek Algılanan Yarar, Web sayfası Güven, Canlı Destek Güven, Canlı Destek, Web Sayfası Kullanım Kalitesi 


\title{
The Impact of Live Support on The Web Page Trust and Web Page Usage Quality: A Research on Online Shopping Sites
}

\begin{abstract}
Increasing online shopping sites and providing easy access to the internet, also increases competition in the online environment. While the options for customers are increasing day by day, it is getting harder to gain customers for e-retailers. One of the main reasons for this is trust and quality. The seller wants to win customers by proving their reliability and quality, while the consumer wants to make sure that their wishes and needs will be met. Easy communication between consumers and sellers is important for them to express themselves. The live support system is an innovative tool to provide online customers with real-time and on-demand support. The aim of this study is to examine the effect of live support system on web page usage quality and web page trust at the online shopping sites. The effect of live support on web page usage quality and web page trust, and the relationship between them which is mainly examined through 8 hypothesis testing. The research was realized on 346 people which are using online shopping sites. Data were collected with a questionnaire which is a frequently used data collection method in the literature, analyzed with SPSS package program. When the research results are examined, positive relationships were found between live support, web page trust and web page usage quality, the hypotheses which is put forward were confirmed.
\end{abstract}

Keywords: Live Support Perceived Benefit, Web Page Trust, Live Support Trust, Live Support, Web Page Usage Quality 


\section{Giriş}

İnternet, her zaman her yerden her şeye erişmenin en uygun yoludur. Böylece online alışverişe yol açmaktadır. Son yıllarda, online alışveriş, iş alanında rekabeti artırarak zirveye ulaşmıştır. Çevrimiçi alışveriş yapmanın avantajlarına rağmen, tüketiciler, web sitelerinin güvenilirliği, bilgi gizliliği, ürün kalitesi ve ayrıca satın alma sonrası hizmet gibi çeşitli faktörler nedeniyle web sitelerinden satın alma konusunda isteksizdir. Bunlardan kaçınmak için, en önemli yol web sitelerine olabildiğince çok müşteri çekmek, tüketici bir kez web sitenizi görüntüledikten sonra ona güven aşlamak ve onlardan sadakat beklemektir (Saini ve Khandelwal, 2019). Tüketiciye güven aşlamak ve isteklerinin karşılanabileceğini ona kanıtlamak için müşteri ile iletişime geçmek önemlidir. Bu durumda tüketicilere çevrimiçi alışverişlerinde yardımcı olmak için bazı teknikler mevcuttur. Online ortamda satıcılar temel ürün veya hizmet bilgilerinin paylaşıp, tüketici görüşlerini forum siteleri veya kendi siteleri üzerinden paylaşabilmektedirler. Buna ek olarak, bazı alışveriş siteleri tüketiciler ve satıcılar arasındaki iletişimi kolaylaştırmak için canlı destek hizmetlerini kullanmaktadır (Stanley, 2005).

Canlı destek, satıcılarla iletişim yoluyla ürün bilgileri sağlayarak ve satıcının varlığını artırarak tüketicilerin ürün, şirket ve web sitesi hakkındaki belirsizliğini azaltmasına yardımcı olur. Tüketiciler ürün bilgisi için satıcılarla canlı sohbet aracılığıyla iletişim kurarak önemli bilgiler elde ederler, böylece web sitelerine veya satın alacakları ürünle/hizmetle ilgili güvenleri ve kalite inançları artar. Sosyal etkileşim dolayısıyla kullanıcının sosyal varlık içindeki etkisi artar. Sosyal varlık üzerindeki etki, bir yandan da samimiyet algısı üzerinde olumlu etkisi yaratır (Ou, Pavlou ve Davison, 2014). Online alışveriş sitelerinde canlı sohbetin kullanımı tüketiciler ve satıcılar arasındaki karşılıklı farkındalığı kolaylaştırarak, konuşmayı geleneksel yüz yüze iletişime benzer hale getirerek sosyal varlığı arttırır (Jiang, Chan, Tan ve Chua, 2010). Artan sosyal varlık ve algılanan etkileşim güveni de artırır (Lu, Fan ve Zhou, 2016). E-ticaret web sitelerinde kullanılmak üzere canlı destek sistemine ilgi son yıllarda önemli ölçüde artmıştır. Sosyal etkileşimi artırarak, tüketici sorularına yanıt vermeyi ve alışveriş deneyimini kişiselleştirmeyi amaçlayan online alışveriş siteleri bunu satın alma riskini azaltmanın en uygun maliyetli yollarından biri olarak görmektedir. Ancak literatürde canlı destek sisteminin etkileri 
ile ilgili yeterli sayıda çalışma bulunmamaktadır (Andrews, 2010).Canlı sohbet ortamının alışveriş sitelerinde kullanımı yaygınlaşmasına rağmen böyle bir ortamın tüketiciler tarafından kullanımı ile ilgili araştırma miktarı hala yetersizdir (Kang, Wang, Tan ve Zhao, 2015). Bu çalışmada, canlı destek sisteminin web sayfası güveni ve web sayfası kullanım kalitesi üzerindeki etkilerini inceleyerek bu araştırma boşluğunu doldurmak amaçlanmaktadır.

\section{Teorik Altyap1}

\section{Canlı Destek}

Canlı destek, işletmelerin Web sitelerini ziyaret edenlerle gerçek zamanlı olarak iletişim kurmalarına veya sohbet etmelerine olanak tanıyan bir Web hizmetidir. Canlı destek uygulamaları, müşterilere anında müşteri desteği ve bilgi sağlamak için yaygın olarak kullanılır. Canlı desteğin kesin özellikleri ve işlevleri uygulamaya göre değişiklik gösterebilir, ancak genel olarak canlı bir sohbet uygulamasından gerçek zamanlı ziyaretçi izleme, özel sohbet pencereleri, görünmez trafik analizi, web sitesi entegrasyonu ve güvenli yönetim kontrolleri sunmasını beklenir. Canlı desteğe, canlı yardım veya canlı sohbet de denebilir (Elmorshidy, 2011). Bu çalışmada canlı destek değişkeni iki alt boyut ile incelenmektedir. Bunlar algılanan yarar ve güven boyutlarıdır.

Güven: Canlı sohbet, göndericiden alıcıya metin tabanlı mesajların anında iletilmesini sağlayan internet üzerinden her türlü iletişimi ifade edebilir (Elmorshidy, 2013). Web tabanlı bir canlı destek sistemini temel amacı, müşterilere müşterinin sorgusuyla ilgili bilgi sağlamaktır (Turel, Connelly ve Fisk, 2013). Canlı destek temsilcisinin açık, güncel, ilgili, doğru, eksiksiz ve güvenilir bilgiler verdiğine ve bu bilgilerin yüksek kalitede olduğuna inanılmaktadır (Guo, Ling ve Liu, 2012). Müşteri hizmetleri, bir kurum içinde önemli rol oynayan en yoğun kaynak kullanan departmanlardan biridir (Cui vd., 2017). Canlı destek sistemlerinde müşterilere yanıt verme süresi, yanıt sayısı ve müşteri temsilcisinin tüketicinin bilgi taleplerini karşılayabilme oranı tüketicilerin sonraki davranışlarını etkiler. Ürün bilgisi perspektifinden, satıc1ların hızlı bir şekilde yanıt vermesi, bilgi arayanların özel sorunların derhal yanıtlayabilmesi tüketicinin düşünce ve davranışının daha net olmasına yardımcı olur (Weiss, Lurie ve MacInnis, 2008). Müşsteriler bir web sitesinde canlı 
destek temsilcilerinin kendilerinin aradığı bilgiyi karşılayabilecek nitelikte olmasını ve verdiği bilgilerin güvenilir olmasını beklerler (Flanagin ve Metzger, 2007). Hizmet kalitesi açısından online alışveriş ortamında canlı destek temsilcisinin verdiği bilgilerin kalitesine güven, önemlidir (Anantharanthan Parasuraman, Berry ve Zeithaml, 1991).

Algılanan Yarar: Müşteriye sunulan hizmetin kalitesi, müşteri memnuniyeti ve rekabet edebilirliği sağlamada en önemli faktörlerden biridir (Ray, Muhanna ve Barney, 2005; Szymanski ve Henard, 2001). Online alışveriş siteleri, müşteri memnuniyetini artırmak ve rekabet avantajı sağlamak için tüccarlar ve müşteriler arasında birebir ilişkiler formüle etmek için canlı sohbet gibi yenilikçi araçlar içeren yeni modeller tanıttılar (Brohman, Watson, Piccoli ve Parasurama, 2003). Canlı destek sistemi, çevrimiçi müşterilerin sorularına gerçek zamanlı yardım ve isteğe bağlı yardım sağlayacak şekilde geleneksel müşteri hizmetleri kanallarını genişletti. Çevrimiçi müşteriler, sorularına çevrimiçi olarak anında yanıt almak için canlı sohbet özelliğini kullanır. Bu aracı kullanmak, e-ticaret web sitelerinin fiziksel mağaza alışveriş deneyimini taklit etmesini sağlar ve tüketicilere satış temsilcileriyle iletişim kurmaları ve ürün beklentilerini ifade etmeleri için bir kanal sağlar (Goes, Ilk, Yue ve Zhao, 2012). Canlı sohbet servislerinin sayısız potansiyel avantajı olmasına rağmen, bu tür sistemlerin başarısı kullanım sırasında karşılaşılan deneyime bağlıdır (Gebauer, 2007; Turel vd., 2013).

Geleneksel telefon çağrılarını yanıtlama yöntemine kıyasla, çevrimiçi sohbet hizmeti interneti kullanır ve bu nedenle düşük maliyetli olarak kabul edilir. Buna ek olarak, bu sanal hizmet genellikle uzun saatler boyunca sunulur ve normal çalışma saatlerinin ötesinde kullanıcılara ek hizmet sunmanın etkili bir yoludur (Schiller, 2016). Canlı destek sistemi işlem maliyetlerini 1,25 \$ 'dan (telefonla) 0,25 \$' a (canlı sohbet yoluyla) düşürdüğü ve çevrimiçi alışverişleri\% 41 artırdığ bildirilmiştir (Zinkhan, Kwak, Morrison ve Peters, 2003). Telefon ve geleneksel e-posta hizmetleriyle karşılaştırıldığında, canlı sohbet tüketicilerin ve satıcıların birbirleriyle etkileşimli ve verimli bir şekilde anında iletişim kurmalarını sağlar (Tezcan, 2011). 


\section{Web Sayfası Güven}

Güven, yaşam akışıyla başa çıkmak için önemli bir husustur. Farklı endüstrilerin, müşterinin güvenilirliğini kavramak için belirli kriterleri vardır. Mesela banka ve sigorta şirketleri için şeffaflık ve bilgi politikaları önemliyken, çevrimiçi bir şirket için markasının ve ürünlerinin kalitesini daha fazla önemli olabilir. Bir satıcı için güven oluşturmak, iş dünyasında olumlu sonuçlara yol açar. Güvenin temel yararı, müşteri ile daha uzun vadeli bir ilişkiler kurma, potansiyel müşterilerin daha büyük bir payına erişme ve ağıdan ağıza pazarlamaya yol açan müşteri sadakatidir (Saini ve Khandelwal, 2019). Güven, uzun soluklu ve kârlı ilişkilerin elde edilmesi üzerindeki etkisi nedeniyle özellikle pazarlama literatüründe özel ilgi görmüştür (Andaleeb, 1996; Grönroos, 1996; Muir ve Moray, 1996; Sirdeshmukh, Singh ve Sabol, 2002). Geleneksel olarak güven, bir kişinin belirli nitelikler hakkındaki algılarından türetilen bir grup inanç olarak tanımlanmış; pazarlamada ise güven, marka, ürün veya hizmetleri, satış görevlilerini ve ürün veya hizmetlerin satın alındığ1 kuruluşu içerir (Ganesan, 1994).

Birçok çalışma, web sitesi bileşenlerinin kullanıcı güvenini etkileyebileceğini kanıtlamıştır. Chang ve Fang (2013), bir web sitesinin beş bileşenini veya özelliğinden bahsetmektedir. Bunlar; web sitesi navigasyonu ve sunumu, bilgilerin yararlılı̆̆ı ve doğruluğu, marka gücü, siparişi yerine getirme durumu ve gizlilik politikasıdır. Bahsedilen bu beş bileşenden üçü kullanıcıların güvenini etkileyebilmektedir. Bunlar navigasyon ve sunum, marka gücü ve siparişlerin yerine getirilmesidir.

\section{Web Sayfası Kullanım Kalitesi}

Bir web sitesinin kalitesi tüketicilerin yararlılığına katkıda bulunan özellikleri olarak tanımlanabilir. Literatür incelendiğinde web sayfası kullanım kalitesi; bilgi kalitesi, kullanım kolaylığı, estetik, tepki süresi, güven oluşturma teknolojileri ve duygusal çekicilik gibi çok sayıda boyut ile belirlemektedir (Aladwani ve Palvia, 2002; Barnes ve Vidgen, 2001; Ranganathan ve Ganapathy, 2002; Vishwanath ve Barnett, 2005). Bu çalışmada web sayfası kullanım kalitesi üç boyuta ayrılarak incelenmektedir. Bunlar verimlilik, tepki süresi ve kullanım kolaylığı boyutlarıdır. 
Verimlilik: Görsel estetik ve online sitenin verimliliği, kullanıcı tercihi ve web sitesi kullanımında önemli bir rol oynamaktadır. Verimlilik, minimum israfla üretim olarak tanımlanır. Web sitesi verimliliği ise zaman veya enerji harcamadan bir web sitesindeki bir görevi veya görevleri tamamlayabilmeyi ifade eder. Web sitesi verimliliğini ikiye ayırabiliriz biri mekanik verimlilik ve diğeri kullanıc verimliliği olarak. Mekanik verimlilik, web sitesinin yüklenme hızı, bilgi verimliliği, tasarım ve programlanma verimliliğini içerir (Heath, 2017). Kullanıcı verimliliği ise bir kullanıcının belirli bir görevi ne kadar iyi ve ne kadar hızlı gerçekleştirdiğini ifade eder. Yani bir kullanıcının gezinme yapısı veya bir ürün sipariş etme süreci gibi bir web sitesinin öğelerini işleme ve kullanma verimliliğini ifade eder (Leuthold, Schmutz, Bargas-Avila, Tuch ve Opwis, 2011).

Kullanım Kolaylı̆̆ı: ISO 9241'e göre BT sistemlerinde kullanım kolaylığı, kullanıcıların belirli ortamlarda belirli hedeflere ulaşmalarında verimlilik, etkinlik ve memnuniyetleri şeklinde açıklanır. Bir web sitesinde kullanılabilirlik, sitede gezinmenin veya internet üzerinden alışveriş yapmanın algılanan kolaylı̆̆ını yansıtır (Abbott, Chiang ve Hwang, 2000). Web sitesi kullanılabilirliği, kullanıcının sistemi yönetmeyi ve temel işlevleri öğrenebilme kolaylığını, sitenin tasarım verimliliğini, hatadan kaçınma derecesini ve kullanıcının genel memnuniyetini içerir (Nielsen, 1994). Web sitesi kullanılabilirliği, kullanıcı arayüzlerinin ne kadar kolay kullanılacağını değerlendiren bir kalite özelliği şeklinde de açıklanmaktadır (Nielsen, 2003). Bu tanımlardan da anlaşılacağı üzere kullanım kolaylığı kavramı ile kullanılabilirlik aynı kavramlardır. Literatürde özellikle e-ticaret literatüründe kullanılabilirlik terimi daha sık kullanılmaktadır (Flavián, Guinalíu ve Gurrea, 2006).

Tepki Süresi: Web servislerinin kullanıcıları tarafından verilen işlemlere hızlı bir şekilde yanit vermesi gerekir (Amannejad, Krishnamurthy ve Far, 2016). Bir iş sürecinde iş sürecinin başlaması ile tamamlanması arasındaki süre, operasyonel verimliliğini değerlendirmek için yararlıdır. Döngü süresi olarak adlandırılan bu süre, genel kullanıcı deneyimine, üretkenliğe, organizasyonel gelire ve marka imajina önemli bir katkıda bulunur. Online ortamda sektöründe, uzun tepki süreleri müşteriler beklemek zorunda kaldıkları için rahatsız edici olabilir. Bir e-ticaret sitesinin online ortamdaki uzun döngü süresi, 
müşterilerin kaybedilmesine veya davranışın olumsuz sonuçlanmasına neden olabilir. Tepki süresi web sayfası kalitesi için bir performans ölçütü olarak kullanılır (Ramakrishnan ve Kaur, 2020). Algılanan bekleme süresi arttıkça, bireyin duyuşsal tepkileri gittikçe olumsuz hale gelmektedir (Hui, Thakor ve Gill, 1998).

\section{Değişkenler Arası İlişkiler}

Canlı Destek ile Web Sayfası Güven Arasındaki İlişki: Canlı destek sistemi, ürün, web sayfası navigasyonu, satış ve satış sonrasu süreçler hakkında belirsizlikleri azaltmak için kullanıcıların canlı destek temsilcisi ile gerçek zamanlı iletişime geçerek sorularının yanıtlamasına olanak tanıyan bir sistemdir (Chattaraman, Kwon ve Gilbert, 2012; Go ve Sundar, 2019). Güven, çevrimiçi işlemlerde yer alan belirsizlik derecesinden ötürü, özellikle e-ticaret bağlamında müşterilerle alışverişlerinde merkezi bir rol oynayan çok boyutlu bir yapıdır (Pavlou, 2003). Canlı destek sistemi sayesinde oluşturulan sosyal varlık, satıcılara duyulan güven yoluyla doğrudan veya dolaylı olarak ürün belirsizliğini azaltabilir. Aynı zamanda canlı sohbet tüketicilerin, kendilerini s1cak ve memnun hissetmelerini sağlayarak tüketicilerin duygusal katılımını uyaran ve tüketicilerin sadakati ve tutumu üzerinde olumlu bir etki yaratan, satıcıların tutumların incelemelerine yardımcı olabilir (Jiang vd., 2010; Song ve Zinkhan, 2008). Canlı destek temsilcisi, müşterilerin sorularını anında gerçek zamanlı olarak yanıtlayarak müşterilerin memnuniyet düzeyini artırır. Memnuniyet devamında sadakat ve güveni getir. Dolayısı ile müşteriler online alışveriş sitesinde canlı sohbet düğmesini görseler dahi satış sonrasında da sorularını yanıtlayabilecek bir kişiye kolayca ulaşabileceklerini bilirler (Elmorshidy, 2011). Canlı destek sisteminden ulaşan müşteriye, satıcıların hızlı bir şekilde yanıt vermesi, bilgi arayanların özel soruların derhal yanıtlamaları da web sayfası ve ürünlerle ilgili kapsamlı bilgi ve güvenin gelişmesine yardımcı olur (Weiss vd., 2008). Online alışveriş sitelerinin çoğu, müşterilerini çevrimiçi ortamda tutmak için canlı destek uygulamalarını desteklemektedir. Çünkü canlı destek bağlantısının web sitesinde bulunması web sayfasına duyulan güveni arttırmaktadır (Aydınhan ve Serhat, 2019). 
Canlı Destek ile Web Sayfası Kullanım Kalitesi Arasındaki İişki: Web tabanlı canlı sohbet sistemleri bilgisayar aracılı teknolojik işlevlerdir ve müşterilerin teknolojik işlevlerden beklentileri sürekli artmaktadır. Bu nedenle bu sistemin kullanım kolaylığı ve kalitesi genel müşteri deneyimini ve web sayfasının kalitesini etkileyebilir (McLean ve Wilson, 2016). Web tabanlı canlı sohbet olanakları, müşterilere, aranan bilgileri netleştiren çevrimiçi anlık web desteği sağlar (Chattaraman vd., 2012). Brown ve Chin (2004) canlı destek temsilcilerinden memnuniyetin algılanan hizmet kalitesini doğrudan etkilediğini belirtmektedir. Canlı destek sisteminin beklenen hizmeti karşılama oranı, o sistem tarafından sağlanan hizmet kalitesini ve müşteri memnuniyet derecesini belirleyecektir (Elmorshidy, 2013).

Web Sayfası Kullanım Kalitesi ile Web Sayfası Güven Arasındaki İlişki: Literatürde web sayfası kalite özelliklerinin kullanıcı algıları üzerindeki etkisini inceleyen bazı araştırmacılar, web sitesi kalitesinin çevrimiçi satıcılara olan güveni önemli ölçüde etkileyebileceğini bulmuşlardır (Belanger, Hiller ve Smith, 2002; Fung ve Lee, 1999; McKnight, Cummings ve Chervany, 1998; Pavlou ve Gefen, 2004). Diğer çalışmalar, algılanan web sitesi kalitesinin şirket için algılanan ilk güven ile önemli bir pozitif ilişki olduğu ortaya çıkmaktadır (Gefen, Karahanna ve Straub, 2003; Koufaris ve Hampton-Sosa, 2004; McKnight, Choudhury ve Kacmar, 2002).

\section{Metodoloji ve Hipotezler}

\section{Araştırma Örneklemi}

Bu araştırmada Ana Kütle online alışveriş sitelerini kullanan kullanıcılardan oluşmaktadır.

Veri Toplama Yöntemi ve Ölçümü: Bu çalışmada web sitesinde çevrimiçi canlı desteğin, web sayfası güven ve web sayfası kullanım kalitesine etkisinin araştırılması amaçlanmıştır. Veri toplama yöntemi olarak daha önceki çalışmalarda da sıkça kullanılan anket yöntemi kullanılmıştır. Online alışveriş sitelerini kullanan 346 kullanıcı kişi 43 soruluk anket formuna katılmıştır. Ankette kullanılan sorular için yararlanılan ölçekler;

Web sayfası kullanım kalitesi değişkeni: Ananthanarayanan Parasuraman, Zeithaml ve Malhotra (2005)'nın geliştirdiği E-s Qual; Loiacono, Watson ve Goodhue (2002)'nın geliştirdiği WebQual ve son olarak Wolfinbarger ve 
Gilly (2003)'nin geliştirdiği eTailQ ölçeklerinden yararlanılarak oluşturulmuştur. Web sayfası kullanım kalitesini ölçmek için üç boyutlu bir ölçek kullanılmıştır. 8 ifade ile web sitesi verimliliği, 20 ifade ile web sayfası kullanım kolaylığı ve 3 ifade ile tepki süresi ölçümlenmiştir.

Web sayfası güven değişkeni: Loiacono vd. (2002)'nin geliştirdiği WebQual ölçeğinden yararlanılmıştır. Web Sayfası Güven ölçeği kullanılarak ölçümlenmiştir. 3 ifadeden oluşmaktadır.

Canlı destek değişkeni: İki boyutlu McLean ve Osei-Frimpong (2017) ‘un araştırmasında yararlandığı ölçekler kullanılmıştır. Canlı destek güven boyutu 4 ifade ile, canlı destek algılanan yarar boyutu 5 ifade ile ölçümlenmiştir.

Bu çalışmada kullanılan tüm ölçekler ( $1=$ Kesinlikle Katılmıyorum $5=\mathrm{Ke}-$ sinlikle Katılıyorum) şeklinde 5 aralıklı Liker tipi ölçeklerdir. Ayrıca ankettin küçük bir kısmında demografik bilgiler yer almaktadır. Anketi cevaplayanlardan istenen demografik bilgiler cinsiyet, eğitim seviyesi, yaş, meslek, gelir durumu şeklindedir.

\section{Araştırmanın Modeli ve Hipotezler}

Araştırma konusuna bağlı olarak yapılan literatür çalışması neticesinde Şekil 1'de ki model kurulmuştur. Sekiz hipotez test edilmektedir.

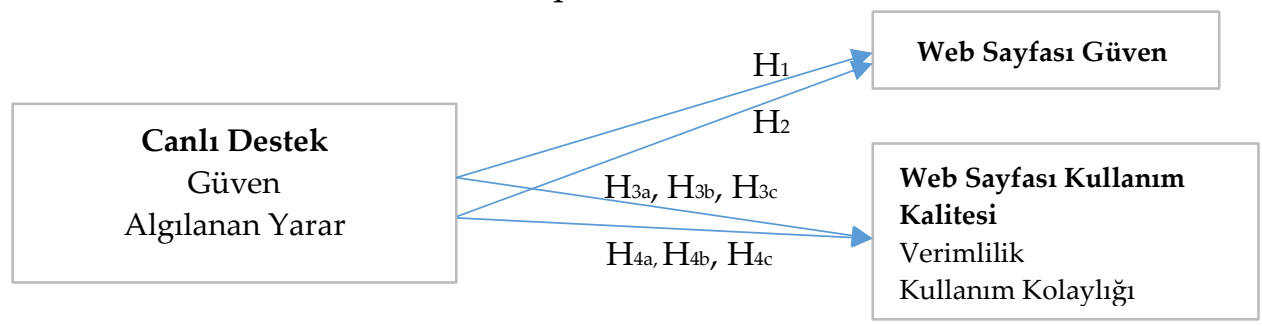

\section{Hipotezler}

Şekil 1. Araştırma Modeli

Hı: Canlı Destek Güven Boyutu, Web Sayfasına Güven Boyutunu pozitif etkiler.

$\mathrm{H}_{2}$ : Canlı Destek Algılanan Yarar Boyutu, Web Sayfasına Güven boyutunu pozitif etkiler. 
- Hзa: Canlı Destek Güven Boyutu, Web Sayfası Kullanım Kalitesi Verimllik Boyutunu pozitif etkiler.

- Hzb: Canlı Destek Güven Boyutu, Web Sayfası Kullanım Kalitesi Kullanım Kolaylığı Boyutunu pozitif etkiler.

- Hзc: Canlı Destek Güven Boyutu, Web Sayfası Kullanım Kalitesi Tepki Süresi Boyutunu pozitif etkiler.

- Ha: Canlı Destek Algılanan Yarar Boyutu, Web Sayfası Kullanım Kalitesi Verimlilik Boyutunu pozitif etkiler.

- Hab: Canlı Destek Algılanan Yarar Boyutu, Web Sayfası Kullanım Kalitesi Kullanım Kolaylığı Boyutunu pozitif etkiler.

- H4c: Canlı Destek Algılanan Yarar Boyutu, Web Sayfası Kullanım Kalitesi Tepki Süresi Boyutunu pozitif etkiler.

\section{Araştırma Bulguları ve Değerlendirme}

Araştırma verileri SPSS programını kullanarak analize tabii tutulmuş ve sonuçlar elde edilmiştir. Araştırmada ilk olarak 346 kişiden oluşan katılımcıların demografik bilgilerine yer verilmiştir. Bu kapsamda Tablo 1'de elde edilen verilere yer verilmiştir.

Tablo 1. Katılımcılarn Demografik Özellikleri

\begin{tabular}{|c|c|c|c|}
\hline & & Frekans & Yüzde \% \\
\hline \multirow[t]{2}{*}{ Cinsiyet } & Erkek & 213 & 62 \\
\hline & Kadın & 133 & 38 \\
\hline Toplam & & 346 & 100 \\
\hline \multirow[t]{4}{*}{ Yaş } & $18-25$ & 138 & 40 \\
\hline & $25-34$ & 133 & 38 \\
\hline & $35-44$ & 48 & 14 \\
\hline & 45 ve üzeri & 27 & 8 \\
\hline Toplam & & 346 & 100 \\
\hline \multirow[t]{4}{*}{ Eğitim Durumu } & İlköğretim & 24 & 7 \\
\hline & Lise & 62 & 18 \\
\hline & Üniversite & 227 & 66 \\
\hline & Lisansüstü & 33 & 9 \\
\hline Toplam & & 346 & 100 \\
\hline \multirow[t]{4}{*}{ Meslek } & Öğrenci & 114 & 33 \\
\hline & Kamu Çalışanı & 39 & 11 \\
\hline & Özel Sektör Çalışanı & 127 & 37 \\
\hline & Serbest Meslek Çalışanı & 66 & 19 \\
\hline Toplam & & 346 & 100 \\
\hline \multirow{2}{*}{ Aylık Gelir } & 1000 TL'den az & 123 & 35 \\
\hline & $1000-2000 \mathrm{TL}$ & 67 & 19 \\
\hline
\end{tabular}




\begin{tabular}{llll}
\hline & $2001-3000$ TL & 61 & 18 \\
\cline { 2 - 4 } & $3001-5000$ TL & 62 & 18 \\
\cline { 2 - 4 } & 5000 TL'den fazla & 33 & 10 \\
\hline Toplam & & $\mathbf{3 4 6}$ & $\mathbf{1 0 0}$ \\
\hline
\end{tabular}

\section{Faktör Analizleri}

Araştırmada kullanılan ölçeğin yapısal geçerliliğinin test edilmesinde sıkça kullanılan bir yöntem olan faktör analizi ile ölçeği meydana getiren soruların birbirleriyle nasıl kümelendikleri belirlenir. Tablo 1'de araştırmaya dahil edilen örneklem yeterliliğini gösteren Kaiser-Mayer-Olkin (KMO) katsayısı ve değişkenler arasında genel olarak anlamlı korelasyonlar olup olmadığını gösteren Barlett's küresellik test sonuçları verilmiştir.

Tablo 2. KMO ve Barlett's Test Sonuçları

\begin{tabular}{lll}
\hline \multicolumn{2}{l}{ Kaiser-Meyer-Olkin Measure of Sampling Adequacy. } &, 938 \\
\hline Bartlett's Test of Sphericity & Approx. Chi-Square & 6451,266 \\
\cline { 2 - 3 } & Df & 861 \\
\cline { 2 - 3 } & Sig. &, 000 \\
\hline
\end{tabular}

SPSS programı ile analiz edilen bu araştırmada KMO değeri 0,938 olarak bulunmuştur. Bulunan değer, örneklemin uygun olduğunu ve örneklemin yapılacak faktör analizi açısından çok iyi derecede yeterli olduğu söylenebilir (Field, 2009).

Yapılan Barlett's testinde ki-kare değeri 6451,266 ve anlamlılık ise 0,000 $(\mathrm{P}<0,05)$ bulunmuştur. Bu değer ise değişkenler arasında faktör analizine uygun ilişkilerin var olduğunu gösterir ve araştırma da kullanılan verilerin faktör analizine uygunluğunu belirtmektedir.

Araştırma da yapılan keşifsel faktör analizinde, araştırmada kullanılan 43 soru öngörüldügüü gibi 6 faktöre ayrılmıştır. Bu faktörler Canlı Destek Güven ve Algılanan Yarar Boyutu, Web Sayfasına Güven ve Web Sayfası Kullanım Kalitesi Verimlilik, Kullanım Kolaylı̆̆ı ile Tepki Süresi boyutlanıdır. Bu amaçla yapılan faktör analizi değerleri Tablo 3'de yer almaktadır. Açıklanan toplam varyans ise tüm değişkenler için \%78,499 tur.

\section{Tablo 3. Faktör Analizi Sonuçları}

\begin{tabular}{lll}
\hline \multicolumn{2}{l}{ CANLI DESTEK } & \\
\hline Güven & & \\
\hline 1. & Canlı sohbet temsilcisinin davranışı güven aşlar. &, 756 \\
\hline 2. & Canlı sohbet temsilcisi ile görüşmelerimde kendimi güvende hissederim. &, 762 \\
\hline 3. & Canlı sohbet temsilcisi sürekli olarak kibar davranır. &, 735 \\
\hline
\end{tabular}


Web Sayfası Canlı Desteğin, Web Sayfası Güven Ve Web Sayfası Kullanım Kalitesine Etkisi: Online Alışveriş Siteleri Üzerine Bir Araştırma

\begin{tabular}{|c|c|c|}
\hline 4. & Canlı sohbet temsilcisi sorularımı cevaplamak için gereken bilgiye sahiptir. & ,707 \\
\hline \multicolumn{3}{|c|}{ Algilanan Yarar } \\
\hline 1. & Canlı sohbet sistemi huzlı bir şekilde görevleri yerine getirmemi sağlıyor. & , 825 \\
\hline 2. & Canlı sohbet sistemi performansımı artırıyor & 872 \\
\hline 3. & Canlı sohbet sistemini kullanmak verimliliğimi arttırıyor. & 863 \\
\hline 4. & Canlı sohbet sistemini kullanmak, etkinliğimi artırıor. & 872 \\
\hline 5. & Canlı sohbet sistemi faydalıdır. & ,769 \\
\hline \multicolumn{3}{|c|}{ WEB SAYFASI GÜVEN } \\
\hline 1. & Web sitesindeki işlemlerimde kendimi güvende hissediyorum. & ,708 \\
\hline 2. & Kişisel bilgilerimi güvende tutmak için Web sitesine güveniyorum. & ,741 \\
\hline 3. & Web sitesi yöneticilerine, kişisel bilgilerimi kötüye kullanmayacağına inanıyorum. & 570 \\
\hline \multicolumn{3}{|c|}{ WEB SAYFASI KULLANIM KALITESİ } \\
\hline \multicolumn{3}{|c|}{ Verimlilik } \\
\hline 1. & Bu site ihtiyacım olanı bulmayı kolaylaştırıyor. & ,554 \\
\hline 2. & Bu site herhangi bir yere ulaşmayı kolaylaştırır & 625 \\
\hline 3. & Bir işlemi hızlı bir şekilde tamamlamamı sağlar. & ,704 \\
\hline 4. & Bu sitedeki bilgiler iyi organize edilmiştir. & ,709 \\
\hline 5. & Bu site sayfalarını huzlı yükler. & ,746 \\
\hline 6. & Bu sitenin kullanımı kolaydır. & ,677 \\
\hline 7. & Bu site hızlı bir şekilde açllıyor. & ,743 \\
\hline \multicolumn{3}{|c|}{ Kullanım Kolaylığı } \\
\hline 1. & Web sitesinin organizasyonu ve düzeni, ürünleri aramayı kolaylaştırır. & ,742 \\
\hline 2. & Bu sitede ne yapmak istediğinizi bulmak çok kolay. & ,748 \\
\hline 3. & Site zamanımı boşa harcamıyor. & ,749 \\
\hline 4. & Sitede iyi düzenlenmiş kategoriler var. & ,757 \\
\hline 5. & Web sitesi mantıklı bir şekilde ortaya konmuştur. & ,793 \\
\hline 6. & Ne istediğime hızlıca gidebilirim. & 825 \\
\hline 7. & Bu web sitesinde bir işlemi tamamlamak hızlı ve kolaydır. & ,799 \\
\hline 8. & Bu web sitesinde indirme hızlıdır. & ,783 \\
\hline 9. & Web sitesinde ürünlerin resimleri iyidir. & 681 \\
\hline 10. & İstediğimi minimum sayıda tıklama ile bulabilirim. &, 791 \\
\hline 11. & Site her zaman düzgün çalışıyor. & ,788 \\
\hline 12. & Bu web sitesinde arama fonksiyonu yararlıdır. & 835 \\
\hline 13. & Web sitesi gerektiği gibi çalışır. & ,786 \\
\hline 14. & Bu web sitesinde alışveriş yaparken tüm seçeneklerimin ne olduğunu biliyorum. & ,781 \\
\hline 15. & Sitenin düzeni kusursuz ve basittir. & ,774 \\
\hline \multicolumn{3}{|c|}{ Tepki Süresi } \\
\hline \multicolumn{3}{|c|}{ leme süresi var. } \\
\hline 2. & Web sitesi hızlı bir şekilde yüklenir. & ,732 \\
\hline & Toplam Varyans $\% 78,499$ & \\
\hline
\end{tabular}

Yapılan faktör analizinde, web sayfası kullanım kalitesi verimlilik boyutunun 8. sorusu, web sayfası kullanım kalitesi kullanım kolaylığı boyutunun $1,2,3,19$ ve 20. soruları ile web sayfası kullanım kalitesi tepki süresi boyutunun 3. Sorusu kendi faktörlerine yüklenmedikleri için korelasyon ve regresyon analizlerinde kullanılmamıştır. 
Tüm değişkenler için korelasyon analizi:Araştırma değişkenlerine ait; ortalama, standart sapma ve güvenilirlik değerleri (Cronbach Alpha) Tablo 4' de yer almaktadır. 346 katılımcının ortalamaları değerlendirildiğinde, 5'li likert yapısı kullanıldığı dikkate alındığında ortanca değerin $(2,5)$ üzerinde bir değer olduğu görülmektedir. Cronbach Alfa ise 0.903 ile 0.976 arasında değişmekte olup bulunan bu güven aralığ 10,70 'in üzerindedir (Nunnally ve Bernstein, 1994).

Tablo 4. Korelasyon Analizi

\begin{tabular}{lllllllll}
\hline & & ort & SS & CrA & $\mathbf{1}$ & $\mathbf{2}$ & $\mathbf{3}$ & $\mathbf{4}$ \\
\hline $\mathbf{1}$ & Canlı Destek Güven & 3.49 & 1,020 &, 928 & & & & \\
\hline $\mathbf{2}$ & Canlı Destek Algılanan Yarar & 3,44 & 1,042 &, 959 &, $699^{* *}$ & & & \\
\hline $\mathbf{3}$ & Web Sayfası Güven & 3,30 & 1,031 &, 903 &, $631^{* *}$ &, $534^{* *}$ & &, $562^{* *}$ \\
\hline $\mathbf{4}$ & $\begin{array}{l}\text { Web sayfası Kullanım Kalitesi } \\
\text { Verimlilik }\end{array}$ & 3,82 &, 930 &, 944 &, $437^{* *}$ &, $468^{* *}$ &, $570^{* *}$ \\
\hline $\mathbf{5}$ & $\begin{array}{l}\text { Web sayfası Kullanım Kalitesi } \\
\text { Kullanım Kolaylığ }\end{array}$ & 3,78 &, 901 &, 976 &, $542^{* *}$ &, $567^{* *}$ &, $634^{* *}$ &, $673^{* *}$ \\
\hline $\mathbf{6}$ & $\begin{array}{l}\text { Web sayfası Kullanım Kalitesi } \\
\text { Tepki Süresi }\end{array}$ & 3,31 &, 899 &, 914 &, $484^{* *}$ &, $462^{* *}$ &, $635^{* *}$ &, $683^{* *}$ \\
\hline
\end{tabular}

${ }^{* *} \mathrm{P}<0.01$

Korelasyon katsayı değerlerine bakıldığında bütün değişkenler arasında pozitif bir ilişkinin bulunduğu görülmektedir.

Regresyon Analizi: Çalışmada belirtilen hipotezlerin test edilmesi amacıyla çoklu regresyon analizi kullanılmıştır.

\section{Canlı Destek Boyutlarının Web Sayfası Güven Üzerindeki Etkisi}

Araştırma da ortaya koyulan Model 1 anlamlı (F:43.321, P<0.01) olup, modelde iki adet hipotezin testi gerçekleştirilmektedir. Modelde yer alan bağımsız değişkenlerin, bağımlı değişkenin varyansını açılama değeri, $\mathrm{R}^{2}=0.406$ olarak tespit edilmiştir. Yapılan regresyon analizi sonucunda canlı destek güven boyutu $(\beta=0,504 ; \mathrm{p}<0,01)$ ve canlı destek algllanan yarar boyutu $(\beta=0,181$; $\mathrm{p}<0,01)$ ile web sayfasına güven arasında pozitif yönlü ve anlamlı etkinin olduğu anlaşılmıştır. Elde edilen analiz sonuçları Tablo 5'de belirtilmiştir. Bu sonuçlara göre $\mathrm{H}_{1}$ ve $\mathrm{H}_{2}$ hipotezleri desteklenmiştir. 
Tablo 5. Canlı Destek Güven ve Algılanan Yarar Boyutlarını, Web Sayfası Güven Üzerine Etkisi

\begin{tabular}{llll}
\hline Model 1 & Web Sayfası Güven & & \\
\hline Canlı Destek Güven & Beta & $\mathbf{t}$ & Sig. \\
\hline Canlı Destek Algilanan Yarar &, 504 & 5,212 &, $000^{* *}$ \\
\hline $\boldsymbol{R}^{2}$ &, 182 & 1,977 &, $031^{*}$ \\
$\boldsymbol{F}$ & .406 & & \\
Sig & 43.321 & & \\
${ }^{*} \mathrm{P}<0.05{ }^{* *} \mathrm{P}<0.01$ & .000 & &
\end{tabular}

Canlı Destek Boyutlarmın Web Sayfası Kullanım Kalitesi Verimlilik Boyutu Üzerindeki Etkisi

Araştırma da ortaya koyulan Model 2 anlamlı (F:19.553, P<0.01) olup, model de iki adet hipotezin testi gerçekleştirilmektedir. Modelde yer alan bağımsız değişkenlerin, bağımlı değişkenin varyansını açıklama değeri, $R^{2}=0.230$ olarak tespit edilmiştir. Regresyon analizi sonuçlarına göre canlı destek güven boyutu $(\beta=0,215 ; \mathrm{p}<0,05)$ ve canlı destek algilanan yarar boyutu $(\beta=0,318$; $\mathrm{p}<0,01)$ ile web sayfasına kullanım kalitesi verimlilik boyutu arasında pozitif yönlü ve anlamlı etkinin olduğu anlaşılmıştır. Elde edilen analiz sonuçları Tablo 6' da belirtilmiştir. Bu sonuçlara göre $\mathrm{H}_{3 a}$ ve $\mathrm{H}_{4 a}$ hipotezleri desteklenmiştir.

Tablo 6. Canlı Destek Güven ve Algılanan Yarar Boyutlarnnn, Web Sayfası Kullanim Kalitesi Verimlilik Boyutu Üzerine Etkisi

\begin{tabular}{llll}
\hline Model 2 & \multicolumn{3}{l}{$\begin{array}{l}\text { Web sayfası Kullanım Kalitesi } \\
\text { Verimlilik }\end{array}$} \\
\hline & Beta & $\mathbf{t}$ & Sig. \\
\hline Canlı Destek Güven &, 215 & 1,96 &, $026^{*}$ \\
\hline Canlı Destek Algilanan Yarar &, 318 & 2,888 &, $002^{* *}$ \\
\hline $\boldsymbol{R}^{2}$ & .230 & & \\
$\boldsymbol{F}$ & 19.553 & & \\
Sig & .000 & & \\
\hline
\end{tabular}

${ }^{* *} \mathrm{P}<0.01,{ }^{*} \mathrm{P}<0.05$

Canlı Destek Boyutlarnın Web Sayfası Kullanım Kalitesi Kullanım Kolaylı̆̆ı Boyutu Üzerindeki Etkisi

Araştırma da ortaya koyulan Model 3 anlamlı (F:19.553, P<0.01) olup, model de iki adet hipotezin testi gerçekleştirilmektedir. Modelde yer alan bağımsız değişkenlerin, bağımlı değişkenin varyansını açıklama değeri, $\mathrm{R}^{2}=0.353$ olarak tespit edilmiştir. Regresyon analizi sonuçlarına göre canlı destek güven 
boyutu $(\beta=0,286 ; \mathrm{p}<0,01)$ ve canlı destek algilanan yarar boyutu $(\beta=0,367$; $\mathrm{p}<0,01)$ ile web sayfasına kullanım kalitesi kullanım kolaylığ sında pozitif yönlü ve anlamlı etkinin olduğu anlaşılmıştır. Elde edilen analiz sonuçları Tablo 7'de belirtilmiştir. Bu sonuçlara göre $\mathrm{H}_{3 \mathrm{~b}}$ ve $\mathrm{H}_{4 \mathrm{~b}}$ hipotezleri desteklenmiştir.

Tablo 7. Canlı Destek Güven ve Algılanan Yarar Boyutlarnnn, Web Sayfası Kullanım Kalitesi Kullanım Kolaylğ̆ Boyutu Üzerine Etkisi

\begin{tabular}{llll}
\hline Model 3 & $\begin{array}{l}\text { Web sayfası Kullanım Kalitesi } \\
\text { Kullanım Kolaylığı }\end{array}$ & \\
\hline & Beta & $\mathbf{t}$ & Sig. \\
\hline Canlı Destek Güven &, 286 & 2,830 &, $002^{* *}$ \\
\hline Canlı Destek Algılanan Yarar &, 367 & 3,636 &, $000^{* *}$ \\
\hline$R^{2}$ & .353 & & \\
$F$ & 34.769 & & \\
Sig & .000 & & \\
\hline
\end{tabular}

${ }^{* *} \mathrm{P}<0.01$

\section{Canlı Destek Boyutlarnnn Web Sayfası Kullanım Kalitesi Tepki Süresi} Boyutu Üzerindeki Etkisi

Araştırma da ortaya koyulan Model 4 anlamlı (F:19.553, P<0.01) olup, model de iki adet hipotezin testi gerçekleştirilmektedir. Modelde yer alan bağımsız değişkenlerin, bağımlı değişkenin varyansını açıklama değeri, $R^{2}=0.252$ olarak tespit edilmiştir Regresyon analizi sonuçlarına göre canlı destek güven boyutu $(\beta=0,314 ; \mathrm{p}<0,01)$ ve canlı destek algilanan yarar boyutu $(\beta=0,242$; $\mathrm{p}<0,05)$ ile web sayfasına kullanım kalitesi tepki süresi boyutu arasında pozitif yönlü ve anlamlı etkinin olduğu anlaşılmıştır. Elde edilen analiz sonuçları Tablo 8' de belirtilmiştir. Bu sonuçlara göre $\mathrm{H}_{3 \mathrm{c}}$ ve $\mathrm{H}_{4 c}$ hipotezleri desteklenmiştir.

Tablo 8. Canlı Destek Güven ve Algılanan Yarar Boyutlarını, Web Sayfası Kullanım Kalitesi Tepki Süresi Boyutu Üzerine Etkisi

\begin{tabular}{llll}
\hline Model 4 & \multicolumn{3}{l}{ Web sayfası Kullanım Kalitesi } \\
& Tepki Süresi & \\
\hline Canlı Destek Güven & Beta & $\mathbf{t}$ & Sig. \\
\hline Canlı Destek Algilanan Yarar &, 314 & 2,830 &, $002^{* *}$ \\
\hline $\boldsymbol{R}^{2}$ &, 242 & 3,636 &, $013^{*}$ \\
$\boldsymbol{F}$ & .252 & & \\
Sig & 21.874 & & \\
\hline
\end{tabular}

${ }^{*} \mathrm{P}<0.05,{ }^{* *} \mathrm{P}<0.01$ 


\section{Hipotezlere İlişkin Sonuçlar}

Araştırma da ortaya koyulan modellerle ilgili olarak yapılan regresyon analizleri ile elde edilen hipotez sonuçları Tablo 9'da yer almaktadır. Bu sonuçlara göre test edilen tüm hipotezler desteklenmiştir.

\section{Tablo 9. Hipotez sonuçları}

\begin{tabular}{lll}
\hline HiPOTEZLER & SONUÇ \\
\hline $\mathrm{H}_{1}$ & Canlı Destek Güven Boyutu, Web Sayfasına Güven Boyutunu pozitif etkiler. & Desteklendi \\
\hline $\mathrm{H}_{2}$ & Canlı Destek Algılanan Yarar Boyutu, Web Sayfasına Güven Boyutunu pozitif etkiler. & Desteklendi \\
\hline $\mathrm{H}_{3 \mathrm{a}}$ & Canlı Destek Güven Boyutu, Web Sayfası Kullanım Kalitesi Verimlilik Boyutunu pozitif etkiler. & Desteklendi \\
\hline $\mathrm{H}_{3 \mathrm{~b}}$ & $\begin{array}{l}\text { Canlı Destek Güven Boyutu, Web Sayfası Kullanım Kalitesi Kullanım Kolaylı̆ı Boyutunu pozitif } \\
\text { etkiler. }\end{array}$ & Desteklendi \\
\hline $\mathrm{H}_{3 \mathrm{c}}$ & Canlı Destek Güven Boyutu, Web Sayfası Kullanım Kalitesi Tepki Süresi Boyutunu pozitif etkiler. & Desteklendi \\
\hline $\mathrm{H}_{4 a}$ & $\begin{array}{l}\text { Canlı Destek Algılanan Yarar Boyutu, Web Sayfası Kullanım Kalitesi Verimlilik Boyutunu pozitif } \\
\text { etkiler. }\end{array}$ & Desteklendi \\
\hline $\mathrm{H}_{4 b}$ & $\begin{array}{l}\text { Canlı Destek Algılanan Yarar Boyutu, Web Sayfası Kullanım Kalitesi Kullanım Kolaylı̆̆ Boyutunu } \\
\text { pozitif etkiler. }\end{array}$ & Desteklendi \\
\hline $\mathrm{H}_{4 c}$ & $\begin{array}{l}\text { Canlı Destek Algllanan Yarar Boyutu, Web Sayfası Kullanım Kalitesi Tepki Süresi Boyutunu pozitif } \\
\text { etkiler. }\end{array}$ & Desteklendi \\
\hline
\end{tabular}

\section{Sonuç ve Öneriler}

Günümüzde online alışveriş siteleri hızla artmakta ve bu alana talep de oldukça yoğundur. Çevrimiçi müşterilerin daha talepkâr olduğu ve sorularına ve endişelerine anında cevap verilmesi gereken bir dönemdeyiz (Elmorshidy, 2013). Bu yoğun sistem içinde müşteri talep ve isteklerinin anlaşılması ve karşılanması rekabet avantajı yakalayabilmek açısından büyük öneme sahiptir. Bunun için de tüketiciler ile iletişim kurmanın hesaplı ve işlevsel bir yöntemleri aranmaktadır. Bu yöntemlerden biri de online alışveriş sitelerinde canlı destek sistemi sağlanmasıdır.

Canlı sohbet araçları, satıcılar ve alıcılar arasında senkron iletişimi teşvik etmek için bir kanal olarak ortaya çıkmıştır (Daniel ve Klimis, 1999). Canlı destek sistemi aynı anda birçok müşteriye yanıt verebilmesi açısından yararlı bir sistemdir. Canlı sohbet hizmeti, işletmeler tarafından müşteri deneyimini geliştirmek için sağlanan nispeten yeni bir araçtır (McLean ve Osei-Frimpong, 2017). Ancak literatürde canlı destek sisteminin etkileri ile ilgili yeterli sayıda çalışma bulunmamaktadır (Andrews, 2010). Son yıllarda e-ticaret web sitelerinde canlı destek sisteminin kullanımı önemli ölçüde artmıştır. Canlı destek sisteminin online alışveriş sitelerinde kullanımının yaygınlaşmasına rağmen böyle bir ortamın tüketiciler tarafından kullanımı ile ilgili araştırma 
miktarı hala yetersizdir (Kang vd., 2015). Bu sebeple literatürdeki bu boşluğu doldurmak amacı ile bu çalışmanın amacı canlı desteğin web sayfası kullanım kalitesi ve web sayfası güveni üzerindeki etkilerini analiz etmek ve aralarındaki ilişkiyi incelemektir.

Sosyal etkileşimi sağlayan, tüketici sorularına yanıt vermeyi ve alışveriş deneyimini kişiselleştirmeyi artıran bu sistem belirsizliği azaltmanın uygun maliyetli bir yolu olarak görülmektedir. Canlı destek sohbeti, müşterilerin sorularını anında, gerçek zamanlı olarak yanıtlayarak müşterilerin memnuniyet düzeyini artırır. Canlı sohbet müşterilerde güveni arttırır (Elmorshidy, 2013). İşletmeler için canlı sohbet hizmetleri, müşterilerle iletişim kurmak için mükemmel bir yöntemdir (Elmorshidy, M Mostafa, El-Moughrabi ve Al-Mezen, 2015). Online alışveriş sitelerinde canlı destek sistemi gerçekten müşterilerle bir güven bağı oluşturmaya yardımcı olur (Ogonowski, Montandon, Botha ve Reyneke, 2014). Basso, Goldberg, Greenspan ve Weimer (2001) çevrimiçi mağazada canlı destek üzerine bir deney yapmıştır. Bunun sonucunda web tabanlı anlık mesajlaşma özelliğine sahip çevrimiçi mağazaların, bu araçlara sahip olmayanlardan daha fazla güven yarattı̆̆ını tespit etmişlerdir. Bu araştırma istatistikleri incelendiğinde de literatürde desteklendiği üzere canlı destek ile web sayfası güven arasında anlamlı bir ilişki olduğu ortaya çıkmaktadir.

Yine bu araştırma verileri incelendiğinde online alışveriş sitelerinde canlı destek sistemi ile web sayfası kullanım kalitesi arasında anlamlı bir ilişki olduğu ortaya çıkmaktadır. Åberg ve Shahmehri (2000) canlı destek performansını değerlendirmek için bir prototip sistemi geliştirdiler. Canlı web desteğinin, çevrimiçi mağazaların alaka düzeyi, etkinlik, tutum ve öğrenilebilirlik açısından kullanılabilirliğini geliştirebileceğini buldular. Canlı destek temsilcileri kullanıcılara profesyonel bilgi veya tavsiye verebilirlerse, bu online web sitesinin kalitesini yükseltecektir. Buna bağlı olarak da, müşterilerin web sayfasına güvenini artacak ve daha yüksek satın alma eğilimi sağlayacaktır (Tan, Wang ve Tan, 2016).

Canlı destek sistemi, temsilcilerinin aynı anda üç ila on sohbet oturumunu izleyebilmesi açısından da yararlı bir sistemdir (Elmorshidy vd., 2015). Canlı destek sistemi online alışveriş sitelerine sosyal boyut kazandırmaktadır (Wang, Baker, Wagner ve Wakefield, 2007). E-ticaret web sitelerindeki canlı sohbet hizmetleri, satın alma işlemi sırasında müşterinin sosyal etkileşim gereksinimlerine yanıt verir (Childers, Carr, Peck ve Carson, 2001). Bu etkileşim 
müşteri sadakatini artırmaya ve olumlu müşteri ilişkileri kurmaya yardımcı olur (Salomonson, Åberg ve Allwood, 2012). Tüketiciler için, canlı sohbet hizmetleri web tabanlı satın almada riskleri azaltır(Elmorshidy, 2011; McLean ve Osei-Frimpong, 2017). Canlı sohbet düğmesinin varlığı kullanıcıları rahatlatır ve web sitelerinin ilk izlenimlerini artırır (Elmorshidy, 2011). Bu sonuçlara göre tüketicilerin web sayfasına güven duymaları ve web sayfası kullanım kalite algılarını iyileştirmek için canlı destek sisteminin online mağaza içerisinde bulunması işletmeler ve tüketiciler için pozitif bir durumdur. Günümüz dünyasında özellikle online alışveriş bağlamında rekabetin sürekli arttığı bir gerçektir. Bu ortamda işletmelerin rekabet avantajı ve farkındalık sağlayabilmeleri, online alışveriş sitelerinde kullanım kalitesi ve web sayfası güvenini artırmaları için bu araştırmayı kanıt sayarak bu alanda gelişmeleri bir zorunluluktur. 
EXTENDED ABSTRACT

\title{
The Impact Of Live Support On The Web Page Trust And Web Page Usage Quality: A Research on Online Shopping Sites
}

\author{
Emine Aydinhan - Serhat Erat \\ Gebze Technical University
}

Considering the advantages of online shopping for business in recent years, competition in online shopping has rapidly increased and reached its peak. Although the advantages of shopping online, consumers are reluctant to purchase from websites due to various factors such as website reliability, information confidentiality, product quality, after-purchase service. The most important way to avoid all of these in terms of e-commerce businesses is to pull as many customers to their websit and after consumers view the website once, to give confidence to them and expect loyalty from them (Saini and Khandelwal, 2019). It is important to get in contact with the consumeristic in order to instill confidence in them and to prove that their wishes can be met. In the online environment, sellers advertise their products by sharing basic product or service information. Consumers share their opinions on forum sites or their own sites. In addition, some online shopping sites use live support services to facilitate the communication between consumers and sellers (Stanley, 2005).

Live support basically communicates with the sellers and provides consumers the information that they are curious about the product. Moreover, live support increases visibility of sellers and helps consumers by reduce uncertainty about the product, company, website. By communicating with sellers via live support about product information, consumers (as the ones looking for information) receive important information and their confidence and perception about quality in the sellers' website or the product/service increase. Consequently, user's influence in social interaction goes up.The increase of the consumer's in the social being also affects the development of the sense of sincerity (Ou, Pavlou and Davison, 2014). Effi- 
cient usage of live support increases reciprocal awareness between consumers and sellers, making conversation similar to traditional face-to-face communication, which increases social being (Jiang, Chan, Tan and Chua, 2010). Increased social interaction also increases confidence ( $\mathrm{Lu}$, Fan and Zhou, 2016). The interest in the live support system, especially for use in ecommerce sites, has increased to a considerable extent in recent years. Online shopping sites aim to respond to consumer questions, and personalize shopping experience by increasing sosyal interaction. They perceive this as one of the optimum relevant cost methods to decrease the risk of purchasing. However, research in the literature with the impacts of the live support system are very limited. (Andrews, 2010). Although the usage of live support environments on shopping sites has become widespread, the amount of research on the usage of such an environment by consumers is still insufficient (Kang at all., 2015). At that research, it is purposed to fill the void of this research by examining the effects of live support system on web page trust and web page usage quality.

Main population of this study consists of users using online shopping sites. The questionnaire method is used which was frequently used in previous studies as a datum gathering method.346 users of online shopping sites participated in a questionnaire with 43 questions. In consequence of the literature research, eight hypotheses are tested depending on the research subject.

The survey datum was checked up by using the SPSS programme and the results have been obtained. At the study, the demographic information of the participants, consisting of 346 people, was firstly included. Factor analysis which is commonly used to test the structural validness of the module used in the research has been performed. It was specified how the questions that make up the scale were come together in heaps with each other with this analysis. Kaiser-Meyer-Olkin ((KMO) parameter test, which shows the sample adequacy included in the study, and Bartlett's test of sphericity, which shows whether there are generally significant correlations between the variables, were employed. KMO value was found to be 0.938 . Considering the established value, sayable that the sample is suitable and the sample is very sufficient in terms of factor analysis (Field, 2009). The square value in Bartlett's test was 6451,266 and the significance was found $0,000(\mathrm{P}<0.05)$. That valuation specifies that suitable relationships available 
among the variables, and indicates that the datum using in the research is convenient for factor analysis.

In the heuristic factor analysis handled at the research, 43 questions that make up the variables were separated into 6 factors. These factors are Live Support Confidence and Perceived Benefit Dimension, Web Page Using Quality Efficiency, Ease of Handling, and Response Time. The total variance explained is $78.499 \%$ for all variables.

Regarding the research variables; average, standard deviation, and reliability values (Cronbach Alpha) were calculated. When the averages of 346 participants are evaluated, considering the five-point Likert scale structure is used, it is seen that the median value is above 2.5. Cronbach Alpha is everchanging between 0.903 and 0.976 , and this confidence interval found is over 0.70 (Nunnally and Bernstein, 1994). When examined the correlation coefficient values, it has occurred that an affirmative connection between all variance is available.

Multiple regression analysis has used to test the hypothesis stated at the research. The consequence of regression analysis shows which all tested hypotheses were supported.

The statistics of the survey indicate that an important connection between live support and web page confidence is available.. A significant relationship was established between live support and web page usage quality. According to these results, having a live support system in the online store in order to ensure that consumers confident about the web page and improve their perception of web page usage quality is a positive sitiation for businesses and consumers. In the world we live in today, that is a real thatcompetition is constantly increasing, especially in the case of online shopping. In this environment, it is a necessity for businesses to gain competitive advantage and awareness, to increase the quality of usage and web page confidence in online shopping sites, and to consider this research as evidence and to improve in this field.

\section{Kaynakça / References}

Abbott, M., Chiang, K.-P. ve Hwang, Y.-s. (2000). The process of on-line store loyalty formation. ACR North American Advances.

Åberg, J. ve Shahmehri, N. (2000). The role of human Web assistants in e-commerce: an analysis and a usability study. Internet Research, 10(2), 114-125. 
Aladwani, A. M. ve Palvia, P. C. (2002). Developing and validating an instrument for measuring user-perceived web quality. Information $\mathcal{E}$ Management, 39(6), 467-476.

Amannejad, Y., Krishnamurthy, D. ve Far, B. (2016). Predicting web service response time percentiles. Paper presented at the 201612th International Conference on Network and Service Management (CNSM).

Andaleeb, S. S. (1996). An experimental investigation of satisfaction and commitment in marketing channels: the role of trust and dependence. Journal of retailing, 72(1), 77-93.

Andrews, D. C. (2010). Georgetown University. Online customer service chat: Usability and sociability issues. www arraydevcom/commerce/jim/0203-0 l. htm.

Aydınhan, E. ve Serhat, E. (2019). Web sayfasına güven ve canlı desteğin yeniden satın alma niyeti üzerine etkisi: Online alışveriş siteleri üzerine bir araştırma. İstanbul Gelişim Üniversitesi Sosyal Bilimler Dergisi, 6, 123-140.

Barnes, S. J. ve Vidgen, R. (2001). An evaluation of cyber-bookshops: the WebQual method. International Journal of Electronic Commerce, 6(1), 11-30.

Basso, A., Goldberg, D., Greenspan, S. ve Weimer, D. (2001). First impressions: Emotional and cognitive factors underlying judgments of trust e-commerce. Paper presented at the Proceedings of the 3rd ACM conference on Electronic Commerce.

Belanger, F., Hiller, J. S. ve Smith, W. J. (2002). Trustworthiness in electronic commerce: the role of privacy, security, and site attributes. The journal of strategic Information Systems, 11(3-4), 245-270.

Brohman, M. K., Watson, R. T., Piccoli, G. ve Parasurama, A. (2003). Data completeness: a key to effective net-based customer service systems. Communications of the ACM, 46(6), 47-51.

Brown, S. P. ve Chin, W. W. (2004). Satisfying and retaining customers through independent service representatives. Decision Sciences, 35(3), 527-550.

Chang, Y.-S. ve Fang, S.-R. (2013). Antecedents and distinctions between online trust and distrust: Predicting high-and low-risk internet behaviors. Journal of electronic commerce research, 14(2), 149.

Chattaraman, V., Kwon, W.-S. ve Gilbert, J. E. (2012). Virtual agents in retail web sites: Benefits of simulated social interaction for older users. Computers in Human Behavior, 28(6), 2055-2066.

Childers, T. L., Carr, C. L., Peck, J. ve Carson, S. (2001). Hedonic and utilitarian motivations for online retail shopping behavior. Journal of retailing, 77(4), 511-535. 
Cui, L., Huang, S., Wei, F., Tan, C., Duan, C. ve Zhou, M. (2017). Superagent: A customer service chatbot for e-commerce websites. Paper presented at the Proceedings of ACL 2017, System Demonstrations.

Daniel, E. ve Klimis, G. M. (1999). The impact of electronic commerce on market structure:: An evaluation of the electronic market hypothesis. European Management Journal, 17(3), 318-325.

Elmorshidy, A. (2011). Benefits analysis of live customer support chat in E-commerce websites: dimensions of a new success model for live customer support chat. Paper presented at the 2011 10th International Conference on Machine Learning and Applications and Workshops.

Elmorshidy, A. (2013). Applying the technology acceptance and service quality models to live customer support chat for e-commerce websites. Journal of Applied Business Research, 29(2), 589-595.

Elmorshidy, A., M Mostafa, M., El-Moughrabi, I. ve Al-Mezen, H. (2015). Factors influencing live customer support chat services: an empirical investigation in Kuwait. Journal of theoretical and applied electronic commerce research, 10(3), 6376.

Flanagin, A. J. ve Metzger, M. J. (2007). The role of site features, user attributes, and information verification behaviors on the perceived credibility of web-based information. New media $\mathcal{E}$ society, 9(2), 319-342.

Flavián, C., Guinalíu, M. ve Gurrea, R. (2006). The role played by perceived usability, satisfaction and consumer trust on website loyalty. Information $\mathcal{E}$ Management, 43(1), 1-14.

Fung, R. ve Lee, M. (1999). EC-trust (trust in electronic commerce): exploring the antecedent factors. AMCIS 1999 Proceedings, 179.

Ganesan, S. (1994). Determinants of long-term orientation in buyer-seller relationships. Journal of marketing, 58(2), 1-19.

Gebauer, H. (2007). An investigation of antecedents for the development of customer support services in manufacturing companies. Journal of business-to-Business Marketing, 14(3), 59-96.

Gefen, D., Karahanna, E. ve Straub, D. W. (2003). Trust and TAM in online shopping: An integrated model. MIS quarterly, 27(1), 51-90.

Go, E. ve Sundar, S. S. (2019). Humanizing chatbots: The effects of visual, identity and conversational cues on humanness perceptions. Computers in Human Behavior, 97, 304-316. 
Goes, P., Ilk, N., Yue, W. T. ve Zhao, J. L. (2012). Live-chat agent assignments to heterogeneous e-customers under imperfect classification. ACM Transactions on Management Information Systems (TMIS), 2(4), 1-15.

Grönroos, C. (1996). Relationship marketing logic. Asia-Australia marketing journal, $4(1), 7-18$.

Guo, X., Ling, K. C. ve Liu, M. (2012). Evaluating factors influencing consumer satisfaction towards online shopping in China. Asian Social Science, 8(13), 40.

Heath, M. (2017). The effect of multi-device design on website efficiency and user preference.

Hui, M. K., Thakor, M. V. ve Gill, R. (1998). The effect of delay type and service stage on consumers' reactions to waiting. Journal of consumer research, 24(4), 469479.

Jiang, Z., Chan, J., Tan, B. C. ve Chua, W. S. (2010). Effects of interactivity on website involvement and purchase intention. Journal of the Association for information systems, 11(1), 1.

Kang, L., Wang, X., Tan, C.-H. ve Zhao, J. L. (2015). Understanding the antecedents and consequences of live chat use in electronic markets. Journal of Organizational Computing and Electronic Commerce, 25(2), 117-139.

Koufaris, M. ve Hampton-Sosa, W. (2004). The development of initial trust in an online company by new customers. Information \& Management, 41(3), 377397.

Leuthold, S., Schmutz, P., Bargas-Avila, J. A., Tuch, A. N. ve Opwis, K. (2011). Vertical versus dynamic menus on the world wide web: Eye tracking study measuring the influence of menu design and task complexity on user performance and subjective preference. Computers in Human Behavior, 27(1), 459-472.

Loiacono, E. T., Watson, R. T. ve Goodhue, D. L. (2002). WebQual: A measure of website quality. Marketing theory and applications, 13(3), 432-438.

Lu, B., Fan, W. ve Zhou, M. (2016). Social presence, trust, and social commerce purchase intention: An empirical research. Computers in Human Behavior, 56, 225237.

McKnight, D. H., Choudhury, V. ve Kacmar, C. (2002). The impact of initial consumer trust on intentions to transact with a web site: a trust building model. The journal of strategic Information Systems, 11(3-4), 297-323.

McKnight, D. H., Cummings, L. L. ve Chervany, N. L. (1998). Initial trust formation in new organizational relationships. Academy of management Review, 23(3), 473-490. 
McLean, G. ve Osei-Frimpong, K. (2017). Examining satisfaction with the experience during a live chat service encounter-implications for website providers. Computers in Human Behavior, 76, 494-508.

McLean, G. ve Wilson, A. (2016). Evolving the online customer experience... is there a role for online customer support? Computers in Human Behavior, 60, 602-610.

Muir, B. M. ve Moray, N. (1996). Trust in automation. Part II. Experimental studies of trust and human intervention in a process control simulation. Ergonomics, 39(3), 429-460.

Nielsen, J. (1994). Usability Engineering published by Morgan Kaufmann. San Francisco.

Nielsen, J. (2003). Usability 101: Introduction to usability. In.

Nunnally, J. ve Bernstein, I. (1994). Psychometric Theory 3rd edition (MacGraw-Hill, New York).

Ogonowski, A., Montandon, A., Botha, E. ve Reyneke, M. (2014). Should new online stores invest in social presence elements? The effect of social presence on initial trust formation. Journal of Retailing and Consumer Services, 21(4), 482-491.

Ou, C. X., Pavlou, P. A. ve Davison, R. (2014). Swift guanxi in online marketplaces: The role of computer-mediated communication technologies. MIS quarterly, 38(1), 209-230.

Parasuraman, A., Berry, L. L. ve Zeithaml, V. A. (1991). Refinement and reassessment of the SERVQUAL scale. Journal of retailing, 67(4), 420.

Parasuraman, A., Zeithaml, V. A. ve Malhotra, A. (2005). ES-QUAL: A multiple-item scale for assessing electronic service quality. Journal of service research, 7(3), 213-233.

Pavlou, P. A. (2003). Consumer acceptance of electronic commerce: Integrating trust and risk with the technology acceptance model. International Journal of Electronic Commerce, 7(3), 101-134.

Pavlou, P. A. ve Gefen, D. (2004). Building effective online marketplaces with institution-based trust. Information Systems Research, 15(1), 37-59.

Ramakrishnan, R. ve Kaur, A. (2020). Performance evaluation of web service response time probability distribution models for business process cycle time simulation. Journal of Systems and Software, 161, 110480.

Ranganathan, C. ve Ganapathy, S. (2002). Key dimensions of business-to-consumer web sites. Information E Management, 39(6), 457-465.

Ray, G., Muhanna, W. A. ve Barney, J. B. (2005). Information technology and the performance of the customer service process: A resource-based analysis. MIS quarterly, 625-652. 
Saini, B. ve Khandelwal, S. (2019). Trust Is an Important Factor Affecting Consumer Behaviour While Shopping Online. Available at SSRN 3473688.

Salomonson, N., Åberg, A. ve Allwood, J. (2012). Communicative skills that support value creation: A study of B2B interactions between customers and customer service representatives. Industrial Marketing Management, 41(1), 145-155.

Schiller, S. Z. (2016). CHAT for chat: Mediated learning in online chat virtual reference service. Computers in Human Behavior, 65, 651-665.

Sirdeshmukh, D., Singh, J. ve Sabol, B. (2002). Consumer trust, value, and loyalty in relational exchanges. Journal of marketing, 66(1), 15-37.

Song, J. H. ve Zinkhan, G. M. (2008). Determinants of perceived web site interactivity. Journal of marketing, 72(2), 99-113.

Stanley, M. (2005). China internet-creating consumer value in Digital China. In.

Szymanski, D. M. ve Henard, D. H. (2001). Customer satisfaction: A meta-analysis of the empirical evidence. Journal of the Academy of Marketing Science, 29(1), 16.

Tan, X., Wang, Y. ve Tan, Y. (2016). The value of live chat on online purchase.

Tezcan, T. (2011). Design and control of customer service chat systems. Available at SSRN 1964434.

Turel, O., Connelly, C. E. ve Fisk, G. M. (2013). Service with an e-smile: Employee authenticity and customer use of web-based support services. Information $\mathcal{E}$ Management, 50(2-3), 98-104.

Vishwanath, A. ve Barnett, G. A. (2005). An empirical investigation into the structure of bidding in online auctions. Electronic Markets, 15(3), 261-268.

Wang, L. C., Baker, J., Wagner, J. A. ve Wakefield, K. (2007). Can a retail web site be social? Journal of marketing, 71(3), 143-157.

Weiss, A. M., Lurie, N. H. ve MacInnis, D. J. (2008). Listening to strangers: whose responses are valuable, how valuable are they, and why? Journal of marketing research, 45(4), 425-436.

Wolfinbarger, M. ve Gilly, M. C. (2003). eTailQ: dimensionalizing, measuring and predicting etail quality. Journal of retailing, 79(3), 183-198.

Zinkhan, G. M., Kwak, H., Morrison, M. ve Peters, C. O. (2003). Web-based chatting: Consumer communication in cyberspace. Journal of Consumer Psychology, 13(1-2), 17-27. 


\section{Kaynakça Bilgisi / Citation Information}

Aydınhan, E. ve Erat, S. (2021). Web sayfası canlı desteğin, web sayfası güven ve web sayfası kullanım kalitesine etkisi: Online alışveriş siteleri üzerine bir araştırma. OPUS-Uluslararası Toplum Araştırmalarn Dergisi, 17(37), 4535-4562. DOI: 10.26466/opus.687398 